\title{
Applying a Constructionist Frame to Learning about Sustainability
}

\author{
Maria Daskolia ${ }^{1}$, Chronis Kynigos ${ }^{2}$ \\ ${ }^{1}$ Environmental Education Lab, Department of Pedagogy, University of Athens, Athens, Greece \\ ${ }^{2}$ Educational Technology Lab, Department of Pedagogy, University of Athens, Athens, Greece \\ Email: mdaskol@ppp.uoa.gr, kynigos@ppp.uoa.gr
}

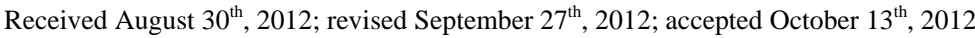

\begin{abstract}
Sustainability as a concept is by nature complex and elusive and therefore difficult to address. Creative thinking is thought among the core abilities needed to be fostered for developing a more integrated understanding of sustainability issues and for achieving a more sustainable world. We argue that Constructionism offers an appropriate frame of identifying and fostering creativity by viewing learning as an experiential process of collaboratively generating new ideas and meaningful digital artifacts through the active engagement with microworld. The study reported in this paper is based on the design and implementation of a pedagogical intervention aiming to engage students in creatively tinkering with a game microworld along with the concept of sustainability. Our analysis focuses on one group of students and examines how ideas and shared understandings of sustainability emerge and evolve along with the creation of a "sustainable city" digital game and through the students' constructive interaction with a related microworld.
\end{abstract}

Keywords: Sustainability; Sustainable City; Creativity; Constructionism; Game Design; Half-Baked Microworld

\section{Dealing Creatively with the "Difficult" Concept of Sustainability}

Sustainability as a concept is by nature complex, ambiguous, context-specific and value-laden, and therefore difficult to address. Complexity stems from its multi-faceted character and the need to apply simultaneously various perspectives to grasp it holistically (Liarakou, Daskolia, \& Flogaitis, 2007). Alongside this there are so many suggestions of what sustainable societies should look like and what changes are needed to achieve sustainability that a great degree of uncertainty and indeterminacy is attached to defining what "most sustainable" means (Wals, 2010a). What is also considered as sustainable now might turn out not to be in the future or it may acquire a different meaning in another context. These features render sustainability quite elusive and ambiguous as a concept and therefore "difficult" to teach if seen through a more traditional pedagogical lens. Yet, sustainability issues are currently among the key topics of most school curricula worldwide. Teaching and learning about them is thought as a sine qua non condition for children and young people to develop a deeper understanding, a willing disposition and an action competence to identify and deal with unsustainable ways of thinking and practices and to bring change in their everyday life and the world (Scott \& Gough, 2004; Jensen \& Schnack, 1997).

So, how can we get students to generate meanings, develop action competence and embody appropriate mindsets around sustainability issues? In this paper, we describe our design of an intervention focused on enhancing creativity within constructionist activity, where students collectively tinker with a digital game based on the idea of sustainable city, and then we discuss our findings from studying its implementation. Creative thinking as the co-construction of new understandings and the sharing of alternative perspectives for the design and pursuit of a more sustainable world is acknowledged among those core abilities needed for better grasping the elusive and relativistic character of the concept and for achieving the goals of sustainability (Wals, 2010b). We argue that constructionism offers an appropriate frame of teaching and learning along this line of though, by allowing the creation of shared meanings and artefacts and by facilitating discussion and negotiation over alternative conceptual suggestions of sustainability while tinkering with related microworld.

The ambiguity characterizing sustainability issues can be turned into a fruitful arena for creative constructionist activity. There is an "appealing vagueness" inherent in the concept (Redclift, 1994) which makes it a "boundary object" (Star \& Griesemer, 1989), that is a "plastic" enough entity to be interpreted and employed by more that one groups or communities in ways that make sense to them, and at the same time a "robust" enough construction that manifests a common identity across all groups and communities. This approach of viewing sustainability is very close to what Meggill (1995) calls "heuristic relativism", that is the recognition that there are limits in the way our perspective allows us to develop a fully-fledged view of a situation and that we need to stand off and explore others' or alternative perspectives as complementary frames for better grasping reality. From a pedagogical point of view, dealing with "boundary" concepts through a heuristic relativism frame of thinking provides many opportunities for teachers and learners to get engaged in dialogical forms of meaning-construction and perspective-sharing and to expand the "boundaries" of their knowing of and being in the world. This is what some would also identify as the essence of creative thinking and learning (Fernández-Cárdenas, 2008). In either way, education has to cultivate learning approaches leading to a creative appropriation of knowledge for students to be able to develop a more integrated understanding of sustainability. It has also to foster 
creativity by facilitating alternative thinking and the emergence of new ideas for empowering young people to envision and design a more sustainable world (Wals, 2010a).

Recent developments in the study of creativity per se emphasize the inherent complexity of the phenomenon, the collective character of creative processes and the "situatedness" of the activities (Daskolia, Dimos, \& Kampylis, 2012). Among current trends in the conceptualization of creativity is that it is not necessarily related to some exceptional ability but rather to a potential everyone is capable of displaying, which may be expressed at various manifestations of a person's everyday life, it is fuelled by collective processes and is possible to be fostered through education. Constructionism both as an epistemology and a learning theory gives distinct emphasis to learners' creative expression and learning through the active exploration, modification and creation of digital artifacts (Papert, 1993; Kafai \& Resnick, 1996). From a constructionist perspective creativity is mainly identified with the generation of new/novel tangible output(s) (the digital artifacts). Digital media-microworlds in particular-are perceived as appropriately designed environments and tools that learners can use to construct "meaningful objects" (Papert, ibid; Kynigos, 2007). These objects are the tangible outputs of their discursive, meaningmaking processes while they interact with the microworld and the learning context; they are at the same time representations of their ideas and understandings of the "world". Constructionism attributes equal importance to the creative tool (the microworld), the creative product (the artifact) and the creative process of learning. Actually there is a symbiotic and synergetic relationship among the three: the microworld is designed to evolve along with the knowledge its users develop while they tinker with it and the artifacts they create.

Particular emphasis is nevertheless placed on the learning context within which both constructionist activities as processes and products occur (Resnick, 1996). Open-ended technological and learning environments that treat microworld as "boundary objects" and allow learners to use them in personally meaningful ways, to collaboratively work with and discuss over them and their key concepts, or to question them and want to modify and improve them, are important coordinates of a context fostering various forms of creativity. We therefore argue that the seeds already exist in the theory of constructionism to address and study creativity through a more integrated conception, which is as a function of a person's ability, presuming an intentional process, occurring within a specific learning environment and entailing the generation of new products (Kampylis \& Valtanen, 2010).

In the study reported in this paper we designed and implemented a pedagogical intervention with the aim to engage students in creatively tinkering with a game microworld along with the concept of sustainability. Our approach moves within a constructionist perspective viewing learning as an experiential process of collaboratively generating new or alternative ideas through the active engagement with the construction and de-construction of meaningful digital artifacts with the use of microworld. In previous studies we have addressed some other parameters of a constructionist approach to teaching and learning about sustainability with game microworld (Kynigos \& Daskolia, 2011). In this study we focus on the creative potential of learning about sustainability through constructionist activities.

\section{The Study}

\section{The Study Context and Participants}

The study presented in this paper is part of a design-based research which was conducted within Metafora, an EU-funded R\&D project (http://www.metafora-project.org). It took place in a secondary education school located in a central area of Athens and was carried out during the last three months of the school year: it started in early March and lasted until mid June 2012. Overall, 11 two-hour sessions were held on a weekly basis. Eighteen students ( 9 girls and 9 boys) participated in the study. They were all members of an afternoon Environmental Education Club, a mixed-class group consisting of 7th, 8th and 9 th graders. Depending on the activities participants were allocated in groups of 6 or in sub-groups of 2 to 3 students. All sessions took place in the school's computer lab and each group was assigned to a computer to work on.

\section{The Scenario and the Tools Employed}

The students' activity was with an E-slate Microworld Kit which we called "Sus-x”, i.e. "Sustainable-system"

(http://etl. ppp.uoa.gr/_content/download/eslate_kits.htm). This is a kit allowing the teacher or student user(s) to construct a sim-city like game so that players do best when they are sensitive and thoughtful about how to ensure or promote sustainability in a particular context (system). A special case of this Microworld Kit addresses "sustainability in the city", which is why we named it "Sus-City".

The Sus-City microworld allows users to create their city background map, by loading, drawing or editing their city image, and place objects on it, the city-sites they want their city to have. They have also to decide on the properties against which they will rate (give specific values to) all city-sites. A set of default (initial) values, a set of threshold values (indicating when the system's sustainability is violated by the player's choices) and the game play rules (maximum time and number of choices) have to be determined by the users. They can also inform players about their game performance through relative messages.

Based on the Sus-City microworld kit we designed a "halfbaked microworld" (Kynigos, 2007) to get students started thinking about urban sustainability and sustainable lifestyles. We deliberately called this game microworld "PerfectVille" (Figure 1) as it was purposefully designed to project an unsustainable model of urban living, which is close to what Lange and Meyer (2009) describe as the "western new middle-class" lifestyle. This is a highly consumerist and hectic way of life which embodies the idea of "the welfare society" as publicized through neo-liberal socio-economic perspectives. Its core elements, high purchasing power to satisfy individual-based needs, the pursuit of social status, high visibility and personal security and high commercialization of quality of life are thought to be at the roots of most unsustainable practices of modern societies.

The students were given the challenge to play the game, discuss what's wrong with it with respect to the sustainability of the city and then change Perfect Ville into their own "sustainable city" game ("My Sus-City"). This task could be carried out by a single student or group of students with the kit alone. However, in the Metafora project we have been developing a system to support learning-to-learn-together activities. The system afford- 


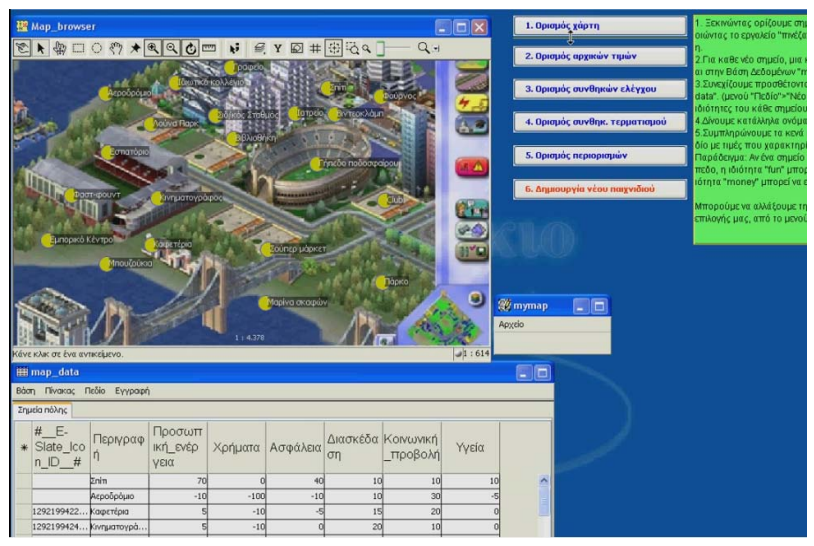

Figure 1.

The PerfectVille game microworld.

ed the students of the study with two more tools which were co-existent and available during their work. One was Lasad, a discussion and argumentation space, and the other a Planning tool space for collaboratively planning and reflecting on their work.

\section{Data Collection and Analysis}

The analysis reported in this paper was based on the data collected from the 8th and 9th session of the study. Audio recording and screen capturing software was used to collect information on the students' discursive interactions within their groups while constructing their game, and on the evolvement of their digital artifacts. These data were coupled with data from the researchers' observation reports. All recorded data were transcribed.

We used microgenetic analysis (Siegler, 2006) within a research design paradigm (Cobb et al., 2003) to analyze how new ideas, alternative perspectives and tangible artifacts (the games) were created within the context of the discursive constructionist activity that the students were involved and as a response to their interaction with the Sus-City microworld, the challenge set to them and the researchers' interventions in facilitating their learning. The analytical framework we employed to identify and discuss creativity is an adaptation of the categorical scheme suggested by Kampylis and Valtanen (2010). It views creativity 1) as being a function of the individual's and group's ability; 2) as being situated at the nexus of several interconnected processes; 3 ) as emerging from a facilitative learning context; and 4) as entailing the generation of new/novel abstract ideas and concrete outputs (digital artifacts). At the same time however, we kept an open mind in our attempt to capture the complexity of the learning situations we were observing and the interweaving and interactions between the different layers of the activity, i.e. student one-to-one interactions, group work, teacher interventions, uses of and changes made to the digital game.

\section{Findings and Discussion}

This section presents and discusses our findings from the analysis of one case (group of students) consisting of two 13-year girls, Christina and Georgia. We provide an overview of the students' engagement with creatively constructing their knowledge about sustainability and collaboratively constructing their game. In presenting the findings we follow the four-category scheme of our analytical framework.

\section{Creativity as a Function of the Individual's and Group's Ability}

Although both girls showed an authentic interest in the task set to them and claimed an equal share in the process, their degree of involvement both in generating new ideas and constructing the game was not alike. We view this-at least to some extent-as a function of their personality and as related to their individual creative ability.

Christina has a strong personality, she is eager enough to take initiatives and contribute with fresh ideas. She is very committed to and fastidious about whatever she undertakes. She always claims a leading role in a team. During the task, Christina had a more active and imaginative participation in all stages of the design process, from the selection of the city background to setting the time frame for the game. She was also quite eloquent in expressing her ideas about sustainability and supporting them with arguments.

Georgia, on the other hand, has a milder personality. She is rather timid and usually leaves to the others both the initiative and the final decision to take. During the task she was less talkative in expressing her views and in indicating changes to the microworld. However, she tried to stay involved in almost all decisions related to design issues and to collaborate with her group mate on almost all aspects of their common work. There were moments that Georgia even surpassed herself by claiming with tenor to take control of the mouse so that she had a more direct interaction with the microworld.

Despite the individual differences in personality and creative expression we would say that some kind of complementarity was developed between the two girls with regard to their participation in the constructionist activity. We view this as an effect of the collaborative processes the two girls were involved in, upon which their group or "middle c" (Moran, 2010) creative potential was dynamically built and expressed throughout the task. This is a special case of creative ability which is fostered and revealed in shared group processes towards fulfilling a meaningful goal and characterizes the collective function of individual members.

\section{Creativity as the Nexus of Several Types of Processes}

Meaning-generation on both the idea of "the sustainable city" and game design was evolved through the students' active display, exchange and negotiation of their ideas while they were collaboratively working on the game microworld. Actually, Sus-City offered a structured agenda for them to collaboratively propose and elaborate on their perspectives with regard to such a complex issue. In their discursive interaction and while "tinkering with" their representations of the sustainable city, the students employed a range of cognitive strategies and communicative patterns to ascribe meaning to sustainability. Our findings indicate that there is a consecutive scalability in the students' employment of various cognitive and communicative processes that goes along with their interpretation of sustainability. These discursive meaning-making processes seem also to be in line with the students' sequential intervention on changing the various fields of the microworld (background map, 
city-site objects, properties, values, etc.). The selected episodes presented below are indicative of this multiple "evolution" that occurred within the context of the students' constructivist engagement.

In the first episode the group goes through the first step in constructing their game, which is to set the city background. They review a set of city-images to decide which one is closer to their idea of a more sustainable city. They observe and discern the particular features of each of them. Their argumentation is rather poor and suggestions are put forward without much justification. However, the students propose three basic features of a sustainable city, which are recurrently identified in later phases of their constructionist engagement: open green spaces, physical water recourses and less reliance in automobiles as a means of urban transport.

Christina: How do you like this one? (She shows at image No. 9). Do you think it's better?

Georgia: Let's see the next one.

Christina: Wait, there're a lot of green places in this too. (They are still talking about image No. 9)

Georgia: Move on...

Christina: Ok... not this one (They look at image No. 15).

Georgia: Neither this one (They look at image No. 2).

Christina: No... not this one (They look at image No. 3).

Georgia: This one (No. 6)... It has lakes too. Can you see?

Christina: Yes, but it has a lot of cars, too. Look at this...

Georgia: This city has too many cars too. (They look again at image No. 9).

The second episode is taken from a subsequent phase of the students' constructionist activity. It is indicative of how their shared representation of the sustainable city has already started to "expand". After they have selected the city-image and changed their game's background map accordingly, the two girls focus on which new city-sites to add and where to put them on the map. This time the students get involved in more elaborated argumentation and negotiation processes over their proposed ideas. They also begin to view urban sustainability not only in terms of a "greener" or "cleaner" environment but as involving several social parameters too, such as the creation of health care services, new job opportunities and community-based organizations. They view all three of them as being in mutual dependence with a "healthier" natural environment. The economic dimension of sustainability also emerges in the students' thought about sustainability, as for example when Georgia casts the idea for an "environmental office" or when Christina suggests adding a "store selling photovoltaic systems" as a business opportunity allowing for profit and being in the benefit of the environment.

Georgia: We can place the "health clinic" over here (she points to the city-map). Close to the park.

Christina: Yes! Cause the air is healthier over there... (They move the "health clinic" closer to the park). What if we put an annex of the "Scouts" organisation over here? (She points to the city-map)

Georgia: Do you think the others (the other group with whom they collaborate) will agree with this? "What do you think if we add 'Scouts' as a new point on the city-map? It is an association that helps protect the environment?" (She types a chat message to the other group).

Georgia: Let's have an "environmental office" too. It's an employment opportunity for the environment.

Christina: Yup, why not? Let's put it here... (She points to a particular place in the city-map).

Christina: Yes... ooh, I got an idea! Let's create a store selling photovoltaic systems. Let's put it here (She points to the map)... It's near the sea.

\section{Creativity as Emerging from a Facilitating Learning Context}

New ideas and understandings of the sustainability concept and game design emerged as a response to the learning environment created by the microworld and the teachers' role in inciting thinking on it. The following excerpt is indicative of how the teacher's (researcher's) intervention to initiate further reflection on the meaning of sustainability, by introducing a schematic representation of the sustainability concept, enhanced students' thinking (Christina's in particular) of alternative sustainability opportunities related to the citizens' sense of wellbeing. The teacher's intention was to provide some scaffolding to the students' thought that would help broaden their perception of sustainability from including just the natural environment. As a result Christina started identifying the "social" dimension of sustainability in their city too:

R1: Ok girls... Can we have a closer look at this scheme? (She shows them a representation of sustainability as being at the intersection of three circles: "environment", "society" and "economy"). What does it say about sustainability?... The city you designed in your game, does it pay enough attention to supporting a healthy community or a vital economy, apart from focusing only on the natural environment?

Christina: Mmm, the people... they should be happy with their life in this city... There are many facilities adding to their well-being... Such as this pool over there (she points to the map)... There is also a small port over there. People can have many nice walks in this city. They could have some nice boat trips on the river too!

The second excpert shows how the glimpse of a new perspective in viewing the city's sustainability strikes Christina as she is prompted by another researcher to review the initial values she had assigned to each of the city-sites. The researcher wanted to help the students develop a better awareness of how their game design choices can shape the players' strategies. By reviewing the "money" values in various city-sites, Christina realises there is a lot of monetary expenditure involved while "using" the city. For people to cherish the various goods and services provided by a city, which add to their quality of life, they have "to pay some fare" in exchange. The exception is with some public goods, such as parks. Quality of life is nevertheless very much connected to needs, and thus a highly socially-constructed concept. Such a perspective offers to the students a novel frame of approaching sustainability as a complex and value-laden issue with many interrelated dimensions.

R3: So, in your game, the player has to go to work (select the "office" city-site) twice to earn more money?

Christina: Yes, in order not to run out of their money resources... Because when visiting most of the city places you spend money. If you go to the "bakery", you spend money... If you go to the "supermarket", it is for buying your dairy foods... You go to the "mall" to buy clothes, etc... To the "clinic", you have to pay the doctors... To the "Concert Hall", you have to pay a ticket to watch an opera... To the "restaurant", you have to pay for the food you are served... To the "club", you pay for your drinks... To the "park", you... Oh no, this is one of the few 
places you don't have to pay anything!

\section{Creativity as the Generation of a New Artifact and a New Conception}

Tinkering with the Sus-City microworld to construct a new "sustainable city" game allowed students to get engaged in meaning-generation processes that led them to a better understanding of the sustainability concept along with the creation of a new artifact. The students made several modifications to Perfect Ville in order to construct a new game that would better represent their idea about sustainability.

Actually the new game (Figure 2) offers a more balanced conception of sustainability compared to Perfect Ville, which is leaning equally into its environmental, social and economic dimensions. More particularly:

- The students altered the city background by selecting and uploading another one. Their representation of a "sustainable city" has more green areas and other natural elements (such as a lake) intertwined in the city's fabric, less cars and a balanced interplay between more and less densely populated areas. The natural environment seems to be the dominant perspective projected in their conception of sustainability. However, the other two dimensions, economy and society, are also present in the students' discussion about the criteria for choosing this image. For example, the students justified the presence of "some skyscrapers" as indicative of the city's economic prosperity, although they would prefer they were less visible in the image. They also argued that their city offers plenty of opportunities for leading a good life. They thus identified quality of life as one of the sustainability's parameters.

- The students deleted four city-sites ("football pitch", "railway station", "luna-park", and "fast-food") as not particularly contributing to the sustainability of their city. They also added eight new city-sites: "The Scouts", "environmental office", "theatre", the "photo voltaics store”, "Hospital", "swimming pool”, "beach", and the "cycling path", as further enhancing the potential for developing more sustainable lifestyles. Actually, their prime criteria for constructing their sustainable city seem to be how close to their personal zone of experience the city sites are and with some of them, how much there is an obvious "environmental-enhancing" function in them. Concerns having to do with the social and economic dimensions of sustainability were less explicit although present. The inclusion of various city-sites declares the idea of a city offering a range of opportunities for diverse groups of people to pursue a quality life according to their needs.

- Among other modifications the two girls moved city-sites on the map several times so that a better matching between their function and the city image was achieved. They also re-set the default values and individual values in all city-sites with the aim to offer a more realistic evaluation of each site. Finally, they changed the threshold conditions and game play rules to render the game more challenging and thus more enjoyable for users to play.

\section{Concluding Remarks}

The study presented in this paper aimed to identify the creative potential offered by a constructionist approach to teaching and learning about sustainability. A pedagogical intervention

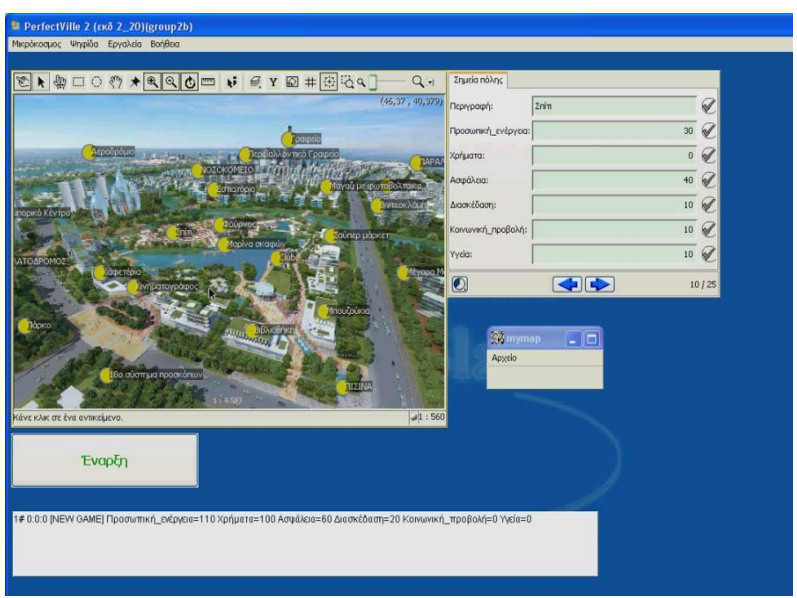

Figure 2.

"My Sus-City" game microworld as created by Christina and Georgia.

was designed to engage Greek High school students in collaboratively tinkering with a microworld on the idea of sustainable city. Our focus was on studying whether and how creativity is a situated dimension of constructionist learning arising from the interaction of the students with a microworld and the learning environment. Our findings suggest that the Sus-City microworld empowered the students to collaboratively articulate, display, and elaborate new ideas and to develop and negotiate alternative perspectives with the view to actively interpret a complex and fuzzy concept such as that of sustainability. Actually the microworld offered not only an appropriate learning environment where students could allow their imagination to deploy and construct their game, but also a structured agenda that prompted them to collaboratively think and share their ideas about sustainability. More particularly, the students were challenged by the task set to them, to create their own "sustainable city" game, and they were aided by the microworld to enter into intentional, shared meaning-making processes that led to the emergence of new understandings and a tangible outcome, their game. Both their discursive interaction over the meaning and features of the sustainable city, their generated ideas and the new game provide evidence of the creative potential of appropriately designed constructionist activities.

Within the context of our study we addressed creativity through a more integrated conception, that is 1) as a function of an individual's and/or group's ability; 2) as being situated at the nexus of several interconnected processes; 3) as occurring within a specific learning environment; and 4) as entailing the generation of new concepts and artifacts. Our proposed analytical framework is supported by the findings of the study. Working within the design research paradigm enabled us to identify creativity in many more hidden dimensions of learning situation than the obvious, and thus to expand the traditional view from within the constructionist community that connects creativity to the generation of digital artifacts only. We argue that this expanded view of the creative potential of learning situations can be of particular value for the theory of constructionism while at the same time it can serve as a useful framework of designing and studying constructionist activities and tools with creativity in mind.

This study gives some insight of how tinkering with a microworld can allow students to enter into intentional and participative meaning-making processes that lead to the emergence 
of new ideas and understandings about difficult concepts, such as that of sustainability. This is of particular importance for Environmental Education and Education for Sustainable Development that are in a constant search for new theoretical approaches and tools to support learning about the complex and multifaceted nature of environmental and sustainability issues in more meaningful ways. Although preliminary empirical evidence is promising, more future research is needed as to whether and how constructionist pedagogical designs can offer appropriate modes and tools for learning about these issues. Moreover, extending constructionist frames of epistemology and learning beyond its traditional subject domains of application, such as mathematics, science and computers education, to social sciences, humanities and the arts is a major challenge yet to be undertaken. This is particularly true for educational domains that promote interdisciplinary, systemic and critical knowledge about complex concepts and issues related to contemporary realities such as those dealt within the context of Environmental Education and Education for Sustainable Development.

\section{Acknowledgements}

The study presented in this paper is funded by EU-R\&D project "Metafora-Learning to Learn Together: A visual language for social orchestration of educational activities” (EC/ FP7, Grant agreement: 257872).

\section{REFERENCES}

Cobb, P., Confrey, J., Disessa, A., Lehrer, P., \& Schauble, L. (2003). Design experiments in educational research. Educational Researcher, 32, 9-13. doi:10.3102/0013189X032001009

Daskolia, M., Dimos, A., \& Kampylis, P. (2012). Secondary teachers' conceptions of creative thinking within the context of Environmental Education. International Journal of Environmental and Science Education, 7, 269-290.

Fernández-Cárdenas, J. M. (2008). The situated aspect of creativity in communicative events: How do children design web pages together? Thinking Skills and Creativity, 3, 203-216. doi:10.1016/j.tsc.2008.09.007

Jensen, B. B., \& Schnack, K. (1997). The action competence approach in environmental education. Environmental Education Research, 3, 163-178. doi:10.1080/1350462970030205

Kafai, Y., \& Resnick, M. (1996). Constructionism in practice. Hoboken, NJ: Taylor \& Francis.
Kampylis, P., \& Valtanen, J. (2010). Redefining creativity-Analyzing definitions, collocations and consequences. Journal of Creative Behavior, 44, 191-214. doi:10.1002/j.2162-6057.2010.tb01333.x

Kynigos, C. (2007). Half-baked logo microworlds as boundary objects in integrated design. Informatics in Education, 6, 1-24.

Kynigos, C., \& Daskolia, M., (2011). Collaborative design and construction of digital games to learn about sustainable lifestyles. In L. Gómez Chova, I. Candel Torres, A. López Martínez (Eds.), Proceedings of the international technology, education, development Conference (pp. 1583-1592). Valencia.

Lange, H., \& Meier, L. (2009). The new middle classes, globalizing lifestyles, consumerism and environmental concern. Heidelberg: Springer.

Liarakou, G., Daskolia, M., \& Flogaitis, E. (2007). Investigating the associative meanings of "sustainability" among Greek kindergarten teachers. International Journal of Interdisciplinary Social Sciences, 1, 29-36.

Meggill, A. (1995). Relativism, or the different senses of objectivity. Academic Questions, 8, 33-39. doi:10.1007/BF02683217

Moran, S. (2010). Creativity in school. In K. Littleton, C. Woods, \& J. K. Staarman (Eds.), International handbook of psychology in education (pp. 319-359). Bingley: Emerald Group Publishing Limited.

Papert, S. (1993). The Childrens' machine. Rethinking school in the age of the computer. New York: Basic Books.

Redclift, M. (1994). Reflections on the "sustainable development" debate. International Journal of Sustainable Development \& World Ecology, 1, 3-21. doi:10.1080/13504509409469856

Resnick, M. (1996). Distributed constructionism. In D. C. Edelson \& E. A. Domeshek (Eds.), Proceedings of the 1996 International Conference on Learning Sciences (pp. 280-284). International Society of the Learning Sciences.

Scott, W., \& Gough, S. (2004). Sustainable development and learning. framing the issues. London: Routledge Falmer.

Siegler, R. S. (2006). Microgenetic analyses of learning. In W. Damon, R. M. Lerner, D. Kuhn, \& R. S. Siegler (Eds.), Handbook of child psychology: Volume 2: Cognition, perception, and language (6th ed., pp. 464-510). Hoboken, NJ: Wiley.

Star, S. L., \& Griesemer, J. R. (1989). Institutional ecology, “translations” and boundary objects: Amateurs and professionals in Berkeley's Museum of Vertebrate Zoology, 1907-1939. Social Studies of Science, 19, 387-420. doi:10.1177/030631289019003001

Wals, A. E. J. (2010a). Mirroring, Gestalt switching and transformative social learning-Stepping stones for developing sustainability competence. International Journal of Sustainability in Higher Education, 11, 380-390. doi:10.1108/14676371011077595

Wals, A. E. J. (2010b). Between knowing what is right and knowing that is it wrong to tell others what is right: On relativism, uncertainty and democracy in environmental and sustainability education. Environmental Education Research, 16, 14.

doi:10.1080/13504620903504099 